\title{
Evaluating wind speed probability distribution models with a novel goodness of fit metric: a Trinidad and Tobago case study
}

\author{
Isa Dookie ${ }^{1} \cdot$ Sean Rocke ${ }^{1} \cdot$ Arvind Singh $^{1} \cdot$ Craig J. Ramlal $^{1}$
}

Received: 12 December 2017 / Accepted: 10 April 2018 / Published online: 17 May 2018

(c) The Author(s) 2018

\begin{abstract}
Wind energy has been explored as a viable alternative to fossil fuels in many small island developing states such as those in the Caribbean for a long time. Central to evaluating the feasibility of any wind energy project is choosing the most appropriate wind speed model. This is a function of the metric used to assess the goodness of fit of the statistical models tested. This paper compares a number of common metrics then proposes an alternative to the application-blind statistical tools commonly used. Wind speeds at two locations are considered: Crown Point, Tobago; and Piarco, Trinidad. Hourly wind speeds over a 15-year period have been analyzed for both sites. The available data is modelled using the Birnbaum-Saunders, Exponential, Gamma, Generalized Extreme Value, Generalized Pareto, Nakagami, Normal, Rayleigh and Weibull probability distributions. The distributions were compared graphically and their parameters were estimated using maximum likelihood estimation. Goodness of fit was assessed using the normalised mean square error testing, Chi-squared testing, Kolmogorov-Smirnov, R-squared, Akaike information criteria and Bayesian information criteria tests and the distributions ranked. The distribution ranking varied widely depending on the test used highlighting the need for a more contextualized goodness of fit metric. With this in mind, the concept of application-specific information criteria (ASIC) for testing goodness of fit is introduced. This allows distributions to be ranked by secondary features which are a function of both the primary data and the application space.
\end{abstract}

Keywords Wind speed · Statistical analysis $\cdot$ Probability distributions $\cdot$ Goodness of fit $\cdot$ Application-specific information criteria (asic)

$\begin{array}{ll}\text { Abbreviations } \\ R^{2} & \text { Coefficient of determination } \\ \chi^{2} & \text { Chi-squared statistic } \\ D^{*} & \text { Two-sample Kolmogorov-Smirnov statistic } \\ \text { ASIC } & \text { Application-specific information criteria } \\ \text { AIC } & \text { Akaike information criterion } \\ \text { BIC } & \text { Bayesian information criterion } \\ \text { NMSE } & \text { Normalised mean square error } \\ \text { PDF } & \text { Probability density function } \\ \text { SIDS } & \text { Small Island Developing States }\end{array}$

Isa Dookie

isa.dookie@sta.uwi.edu

1 Department of Electrical and Computer Engineering, The University of the West Indies, St. Augustine, Trinidad and Tobago

\section{Introduction}

Electricity costs in most Caribbean Small Island Developing States (SIDS) are amongst the highest in the world [1] with majority of electrical energy being produced from imported fossil fuels [2]. As a result, wind energy is increasingly being explored as an alternative source of energy [3] with feasibility studies showing great potential for various islands [4-7]. Conversely, the Caribbean countries are amongst the most wind storm-prone regions in the world suffering from 26 storm impacts in the last 4 years alone [8-10]. These storms have an acute impact on the economies of these small states [11]. Additionally, wind speeds can even impact upon the region's flora and fauna [12].

Given the importance of wind to Caribbean SIDS, it is necessary for the characteristics of the wind be studied closely. Energy studies, storm risk studies and aviation considerations, among others, require the wind to be modelled as accurately and comprehensively as possible. Many studies have aimed at characterizing or comparing wind speed distributions at different locations [13-21]. Several emphasize seasonal variations 
while diurnal variations have also been examined [5]. However, these have either been located outside the Caribbean or have been limited in their exploration of candidate distributions. Furthermore, there is no consensus on the goodness of fit criterion which is most suitable for evaluating the appropriateness of the distribution to a particular application [22].

The paper examines the applicability of probability distributions commonly used to model wind speeds to data available from two locations in Trinidad and Tobago. The relative performance of these distributions is compared using goodness of fit tests. Additionally, the concept of application-specific information criteria (ASIC), is introduced as an improved method for distribution ranking in the case of wind energy studies. Section 2, "Description of Data,"describes the data used for this study, investigates the basic statistical properties and outlines the pre-processing required before utilisation of the data. Section 3, "Methodology" describes the candidate distributions, goodness-of-fit criteria used and the method for parameter estimation. Section 4, "Results and Discussion" displays the fit of the candidate distributions to the data graphically. Several goodness-of-fit tests are used to rank the performance of the distributions. In addition, expected wind energy output from a turbine is estimated and compared to the energy output calculated using the actual wind data. Finally, concluding remarks are given in Sect. 5 .

\section{Description of data}

\section{General}

The locations given in Fig. 1, provide a useful opportunity for comparison as they are both greeted by the same north-easterly trade wind system [23], but are located at sites with differing geography. Crown Point is on a sheltered coast while Piarco is located in-land in an open plain. Piarco also receives some degree of sheltering by mountains to the North.

The dataset consists of the mean hourly wind speeds at Crown Point, Tobago and Piarco, Trinidad (locations indicated in Table 1 for the years 2000-2015, provided by the meteorological offices at airports at both locations and does not include wind direction or peak gust speed. The speeds were recorded in knots, rounded to the nearest knot, and are given in intervals of $1 \mathrm{~h}$ for each hour of the 24-h day for every day of the month. It should be noted that there are data points missing from both datasets. For Piarco, Trinidad, approximately 19 days of data from October 21 to November 9, 2009 are missing. There are

Table 1 Coordinates of wind measurement locations

\begin{tabular}{llll}
\hline Location & Latitude & Longitude & Elevation $(\mathrm{m})$ \\
\hline Crown Point, Tobago & $11.1497 \mathrm{~N}$ & $60.8322 \mathrm{~W}$ & 12 \\
Piarco, Trinidad & $10.5953 \mathrm{~N}$ & $61.3372 \mathrm{~W}$ & 15 \\
\hline
\end{tabular}

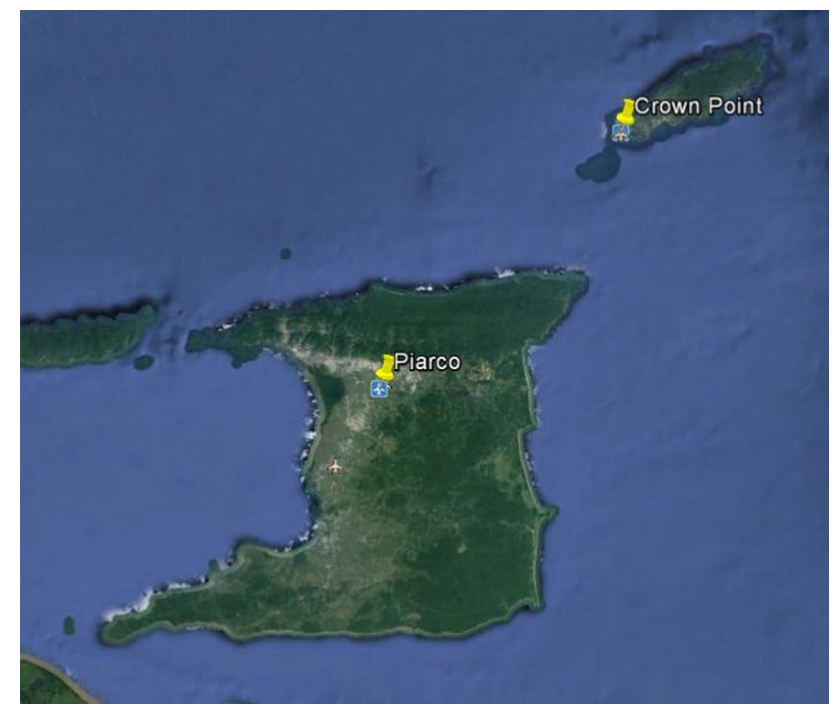

Fig. 1 Map of Trinidad and Tobago illustrating measurement locations [24]

also missing data points for a number of hours on other days. The total number of measurements is 133,083 out of a maximum possible number of 133,656 ( $0.4 \%$ missing data). For Crown Point, the data for the months of July to September, 2001, and August, 2011, are missing. Additionally, some days are missing data for an hour or a few hours. The total number of measurements is 123,429 out of a maximum possible number of 133,656 (7.7\% missing data).

\section{Basic statistics}

Before any pre-processing, the data were described by the statistics given in Tables 2 and 3. Data pre-processing included data inspection for possibly erroneous values:

- As seen in Table 2, at Piarco, the maximum wind speed recorded is 196 knots at 9:00 a.m. on July 3, 2014. The maximum wind speed on that day otherwise was 16 knots, and the average was 8 knots. A wind speed of 196 knots $(363 \mathrm{~km} / \mathrm{h})$ is the equivalent of a Category 5 hurricane [25]. 196 knots surpasses the sustained wind speeds of the strongest hurricane on record, Hurricane Patricia in October 2015 [26]. Records from satellite-based models available online [27] confirm that the measurement is erroneous.

- Similarly, a speed of 94 knots was recorded as the maximum wind speed in 2009. This peak wind speed was recorded on June 12 at 11:00 a.m., followed by a measurement of 84 knots at 12:00 p.m.. The average wind speed on that day without these two measurements was 5.9 knots. These two wind speeds are the equivalent of a Category 2 Hurricane according to the 
Table 2 Basic statistics of wind speeds at Piarco before preprocessing
Table 3 Basic statistics of wind speeds at Crown Point before pre-processing

\begin{tabular}{llcllll}
\hline Year & Number of readings & Max knots & Mean knots & Std. dev. knots & Kurtosis & Skewness \\
\hline 2000 & 8779 & 21 & 5.454 & 4.841 & -0.954 & 0.396 \\
2001 & 8760 & 20 & 5.654 & 4.874 & -1.080 & 0.301 \\
2002 & 8758 & 21 & 5.634 & 4.721 & -0.923 & 0.326 \\
2003 & 8760 & 21 & 5.356 & 4.653 & -0.923 & 0.374 \\
2004 & 8774 & 20 & 4.483 & 4.467 & -0.928 & 0.512 \\
2005 & 8759 & 26 & 4.226 & 4.600 & -0.646 & 0.680 \\
2006 & 8758 & 22 & 4.842 & 4.834 & -0.881 & 0.534 \\
2007 & 8757 & 20 & 4.794 & 4.867 & -0.973 & 0.531 \\
2008 & 8782 & 23 & 4.478 & 4.882 & -0.793 & 0.656 \\
2009 & 8300 & 94 & 4.974 & 5.128 & 16.473 & 1.486 \\
2010 & 8682 & 23 & 5.047 & 5.290 & -0.891 & 0.591 \\
2011 & 8760 & 23 & 5.063 & 5.021 & -0.749 & 0.555 \\
2012 & 8783 & 23 & 5.075 & 5.032 & -0.839 & 0.547 \\
2013 & 8755 & 22 & 5.786 & 5.418 & -0.878 & 0.482 \\
2014 & 8756 & 196 & 5.863 & 5.775 & 132.684 & 4.358 \\
2015 & 2160 & 40 & 6.261 & 5.779 & -0.765 & 0.365 \\
Total & 133,083 & & & & 8.558 & 0.793 \\
Average & & & 5.187 & 5.012 & & \\
\hline
\end{tabular}

\begin{tabular}{lccllrr}
\hline Year & Number of readings & Max knots & Mean knots & Std. dev. knots & Kurtosis & Skewness \\
\hline 2000 & 8762 & 30 & 6.744 & 5.189 & -0.915 & 0.205 \\
2001 & 6519 & 264 & 8.393 & 6.732 & 393.540 & 11.340 \\
2002 & 8036 & 39 & 7.616 & 5.043 & -0.728 & 0.122 \\
2003 & 8722 & 26 & 8.319 & 4.966 & -0.848 & -0.099 \\
2004 & 8770 & 45 & 6.949 & 4.685 & -0.200 & 0.279 \\
2005 & 8735 & 214 & 6.906 & 5.296 & 275.285 & 7.409 \\
2006 & 8598 & 70 & 7.519 & 4.996 & 1.835 & 0.170 \\
2007 & 8752 & 22 & 7.713 & 5.387 & -1.151 & -0.111 \\
2008 & 7063 & 30 & 7.103 & 5.463 & -1.089 & 0.089 \\
2009 & 3655 & 22 & 6.633 & 4.910 & -1.126 & 0.061 \\
2010 & 8654 & 22 & 6.896 & 5.502 & -1.231 & 0.090 \\
2011 & 8725 & 28 & 6.909 & 5.412 & -0.973 & 0.158 \\
2012 & 8772 & 38 & 6.774 & 5.757 & -0.855 & 0.318 \\
2013 & 8749 & 28 & 7.445 & 5.870 & -0.996 & 0.201 \\
2014 & 8757 & 28 & 7.890 & 5.929 & -0.990 & 0.163 \\
2015 & 2160 & 23 & 6.886 & 5.963 & -1.104 & 0.279 \\
Total & 123,429 & & & & & 41.153 \\
Average & & & 7.293 & 5.444 & & 1.292 \\
\hline
\end{tabular}

Saffir-Simpson scale [25]. However, review of archived daily newspapers, for the next day make no mention of the event [28]. Again, no corroborating records were found to confirm these wind speeds [14] and as such, they were deemed erroneous.

- On February 16, 2015 a wind speed of 40 knots was noted at 9:00 a.m. This would be classified as tropi- cal storm wind speeds according to the Saffir-Simpson scale. Online records corroborate the data for the rest of the day.

- At Crown Point, Tobago a maximum wind speed of 264 knots is recorded on November 9, 2001 at 11:00 p.m. This wind speed exceeds the world record maximum 3 second surface wind gust of 220 knots. As such, it can 
safely be concluded that this is an erroneous record. Online records corroborate the data for the rest of the day.

- Similar methods to those utilised above were used to identify 214 knots recorded on November 20, 2005 at 2:00 p.m., 187 knots on April 20, 2001, 96 knots July 17, 2005, 70 knots at 9:00 p.m. on June 20, 2006, 62 knots on
March 20, 2001, 45 knots January 3, 2004 and 39 knots on January 2, 2002 at 11:00 a.m.

All noted erroneous measurements were replaced with null values. Tables 4 and 5 reflects the wind statistics after pre-processing.
Table 4 Basic statistics of wind speeds at Piarco after preprocessing
Table 5 Basic Statistics of Wind Speeds at Crown Point after pre-processing

\begin{tabular}{lclllll}
\hline Year & Number of readings & Max knots & Mean knots & Std. dev. knots & Kurtosis & Skewness \\
\hline 2000 & 8779 & 21 & 5.454 & 4.841 & -0.954 & 0.396 \\
2001 & 8760 & 20 & 5.654 & 4.874 & -1.080 & 0.301 \\
2002 & 8758 & 21 & 5.634 & 4.721 & -0.923 & 0.326 \\
2003 & 8760 & 21 & 5.356 & 4.653 & -0.923 & 0.374 \\
2004 & 8774 & 20 & 4.483 & 4.467 & -0.928 & 0.512 \\
2005 & 8759 & 26 & 4.226 & 4.600 & -0.646 & 0.680 \\
2006 & 8758 & 22 & 4.842 & 4.834 & -0.881 & 0.534 \\
2007 & 8757 & 20 & 4.794 & 4.867 & -0.973 & 0.531 \\
2008 & 8782 & 23 & 4.478 & 4.882 & -0.793 & 0.656 \\
2009 & 8298 & 31 & 4.954 & 4.959 & -1.023 & 0.471 \\
2010 & 8682 & 23 & 5.047 & 5.290 & -0.891 & 0.591 \\
2011 & 8760 & 23 & 5.063 & 5.021 & -0.749 & 0.555 \\
2012 & 8783 & 23 & 5.075 & 5.032 & -0.839 & 0.547 \\
2013 & 8755 & 22 & 5.786 & 5.418 & -0.878 & 0.482 \\
2014 & 8755 & 21 & 5.842 & 5.406 & -1.170 & 0.356 \\
2015 & 2159 & 22 & 6.245 & 5.735 & -1.246 & 0.288 \\
Total & 133,079 & & & & & \\
Average & & & 5.183 & 4.975 & -0.931 & 0.475 \\
\hline
\end{tabular}

\begin{tabular}{lcccccr}
\hline Year & Number of readings & Max & Mean & Std. dev. & Kurtosis & Skewness \\
\hline 2000 & 8762 & 30 & 6.744 & 5.189 & -0.915 & 0.205 \\
2001 & 6516 & 25 & 8.318 & 5.475 & -0.998 & 0.046 \\
2002 & 8035 & 22 & 7.612 & 5.031 & -0.895 & 0.094 \\
2003 & 8722 & 26 & 8.319 & 4.966 & -0.848 & -0.099 \\
2004 & 8769 & 30 & 6.945 & 4.667 & -0.660 & 0.223 \\
2005 & 8733 & 26 & 6.872 & 4.715 & -0.892 & 0.049 \\
2006 & 8597 & 36 & 7.512 & 4.951 & -0.937 & -0.055 \\
2007 & 8752 & 22 & 7.713 & 5.387 & -1.151 & -0.111 \\
2008 & 7063 & 30 & 7.103 & 5.463 & -1.089 & 0.089 \\
2009 & 3655 & 22 & 6.633 & 4.910 & -1.126 & 0.061 \\
2010 & 8654 & 22 & 6.896 & 5.502 & -1.231 & 0.090 \\
2011 & 8725 & 28 & 6.909 & 5.412 & -0.973 & 0.158 \\
2012 & 8772 & 38 & 6.774 & 5.757 & -0.855 & 0.318 \\
2013 & 8749 & 28 & 7.445 & 5.870 & -0.996 & 0.201 \\
2014 & 8757 & 28 & 7.890 & 5.929 & -0.990 & 0.163 \\
2015 & 2160 & 23 & 6.886 & 5.963 & -1.104 & 0.279 \\
Total & 123,421 & & & & & -0.979 \\
Average & & & 7.286 & 5.324 & & 0.107 \\
\hline
\end{tabular}




\section{Methodology}

\section{Distribution fitting}

Typically, wind data is modelled as a Weibull distribution, especially when the aim is to characterise the annual resource [5, 15, 29-32], however, a number of other candidate distributions have been catalogued [33]. For other applications such as statistical analysis of extreme wind speeds, the Weibull (or reverse Weibull) has also been recommended [34] while other distributions such as the generalised extreme value distribution [17] and the generalised pareto [19] have been explored. Agustin [20] encouraged using mixed distributions while confirming the applicability of Weibull. Sarkar et al. [35] identified the weakness of the Weibull distribution as its failure to describe the upper tail. The Rayleigh distribution has also been used as a probability model for wind speed [31], although some applications have found Weibull to be more accurate [32, 36]. Recent studies found autoregressive models [37] and maximum entropy distributions [38] to be better suited to wind speed applications than Weibull or Rayleigh. Alavi et al. [39] found that the Nakagami distribution performed well when compared to other distributions frequently used to model wind speed. Additionally, the Normal and Exponential Distributions were identified as potential candidates via visual inspection of the histogram shape. The Birnbaum-Saunders and Gamma distributions performed well when goodness of fit was assessed using the Akaike information criterion (AIC) and the Bayesian information criterion (BIC) criteria, and were thus included in the comparative analysis (Figs. 2, 3).

\section{Review of probability distribution functions}

The equations defining the probability density functions (PDFs) for various candidate distributions of interest are given below. While by no means exhaustive, the distributions represent those commonly used in the literature.

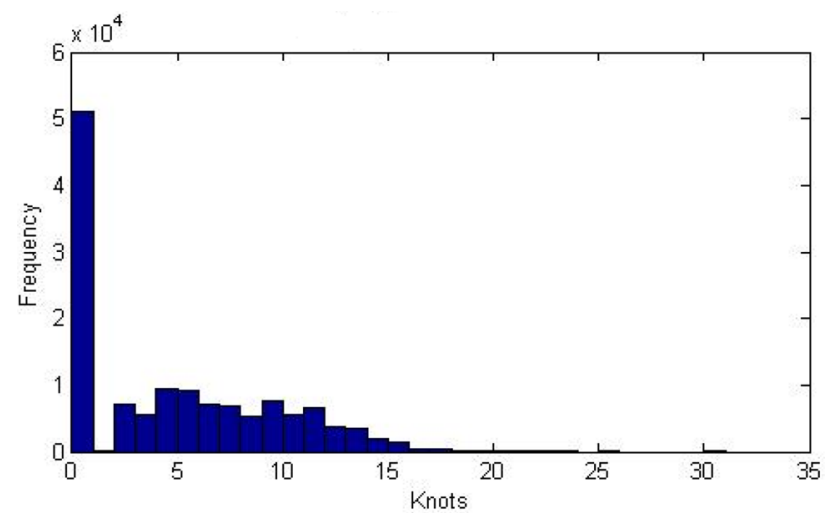

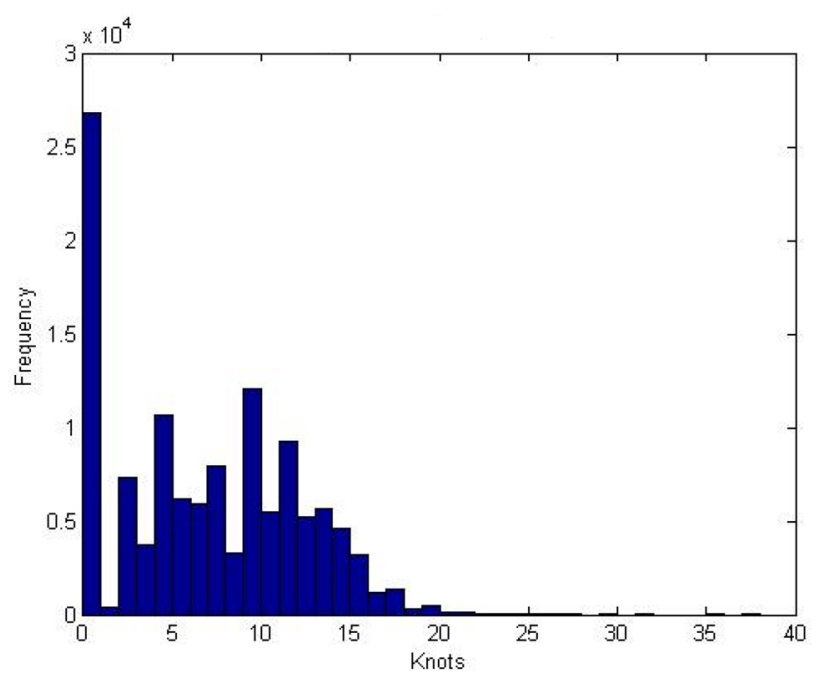

Fig. 3 Histogram of wind speeds at Crown Point

Birnbaum-Saunders

$f(x)=\frac{\sqrt{\frac{x-\mu}{\beta}}+\sqrt{\frac{\beta}{x-\mu}}}{2 \gamma(x-\mu)} \Phi\left(\frac{\sqrt{\frac{x-\mu}{\beta}}-\sqrt{\frac{\beta}{x-\mu}}}{\gamma}\right), \quad x>\mu$,

where $\mu$ is the location parameter, $\gamma>0$ is the shape parameter, $\beta>0$ is the scale parameter and $\Phi(t)=\frac{1}{\sqrt{2 \pi}} \mathrm{e}^{\frac{t^{2}}{2}}[40]$.

\section{Exponential}

$f(x)=\lambda \mathrm{e}^{-\lambda x}, \quad x \geq 0$,

where $\lambda>0$ is the rate parameter [41].

\section{Gamma}

$f(x)=\frac{x^{k-1} \mathrm{e}^{-\frac{x}{\theta}}}{\theta^{k} \Gamma(k)}, \quad x \geq 0$,

where $k, \theta \geq 0$, and $\Gamma(k)=(k-1)$ ! is the gamma function $[42,43]$.

\section{Generalized extreme value}

$f(x)=\frac{1}{\sigma} t(x)^{\xi+1} \mathrm{e}^{-t(x)}$

where

$t(x)= \begin{cases}\left(1+\left(\frac{x-\mu}{\sigma} \xi\right)\right)^{-\frac{1}{\xi}}, & \xi \neq 0, \\ \mathrm{e}^{-\frac{x-\mu}{\sigma},} & \xi=0,\end{cases}$

Fig. 2 Histogram of wind speeds at Piarco 
where $\mu \in \mathbf{R}$ is the location parameter, $\sigma>0$ is the scale parameter and $\xi \in \mathbf{R}$ is the shape parameter [44].

\section{Generalized Pareto}

$f(x)=\frac{1}{\sigma}\left(1+\frac{x-\mu}{\sigma} \xi\right)^{-\left(\frac{\xi+1}{\xi}\right)}$

where $\mu \in \mathbf{R}$ is the location parameter, $\sigma>0$ is the scale parameter and $\xi \in \mathbf{R}$ is the shape parameter [45].

\section{Nakagami}

$f(x)=2\left(\frac{\mu}{\omega}\right)^{\mu} \frac{1}{\Gamma(\mu)} x^{(2 \mu-1)} \mathrm{e}^{-\frac{\mu}{\omega} x^{2}}$

where $\mu$ is the shape parameter and $\omega$ is the spread parameter, for $x>0$ [46].

\section{Normal}

$f(x)=\frac{1}{\sigma \sqrt{2 \pi}} \mathrm{e}^{-\frac{(x-\mu)^{2}}{2 \sigma^{2}}}$,

where $\mu$ is the mean and $\sigma$ is the standard deviation [45].

\section{Rayleigh}

$f(x)=\frac{x}{\sigma^{2}} \mathrm{e}^{\frac{-x^{2}}{2 \sigma^{2}}}$,

where $\sigma$ is the scale parameter [47].

\section{Weibull}

$f(x)= \begin{cases}\frac{k}{\lambda}\left(\frac{x}{\lambda}\right)^{k-1} \mathrm{e}^{-\left(\frac{x}{\lambda}\right)^{k}} & x \geq 0 \\ 0, & x<0,\end{cases}$

where $k>0$ is the shape parameter and $\lambda>0$ is the scale parameter [48].

\section{Parameter estimation}

Several techniques exist for parameter estimation (e.g., [22]). In this work, the parameters for these various distributions were estimated using the maximum likelihood method, which selects as its estimate the parameter value that maximizes the probability of the observed data [49]. This method is popularly used since the resulting estimators are generally asymptotically unbiased and consistent. They also offer the advantage of simplicity in implementation. While this method can be limited through the need to determine closedform estimator solutions, for the distributions of interest in this work, these can be readily obtained [22].

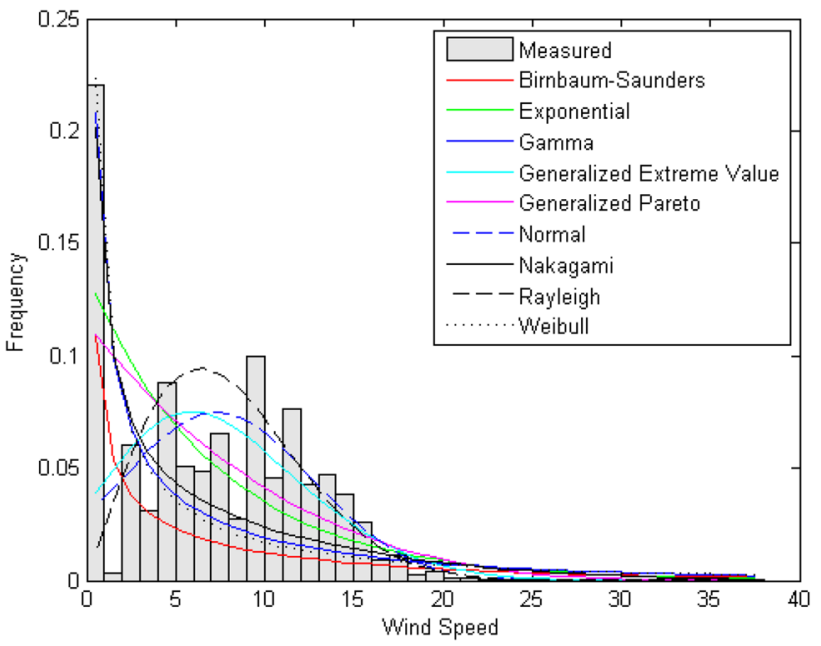

Fig. 4 Wind distribution at Crown Point

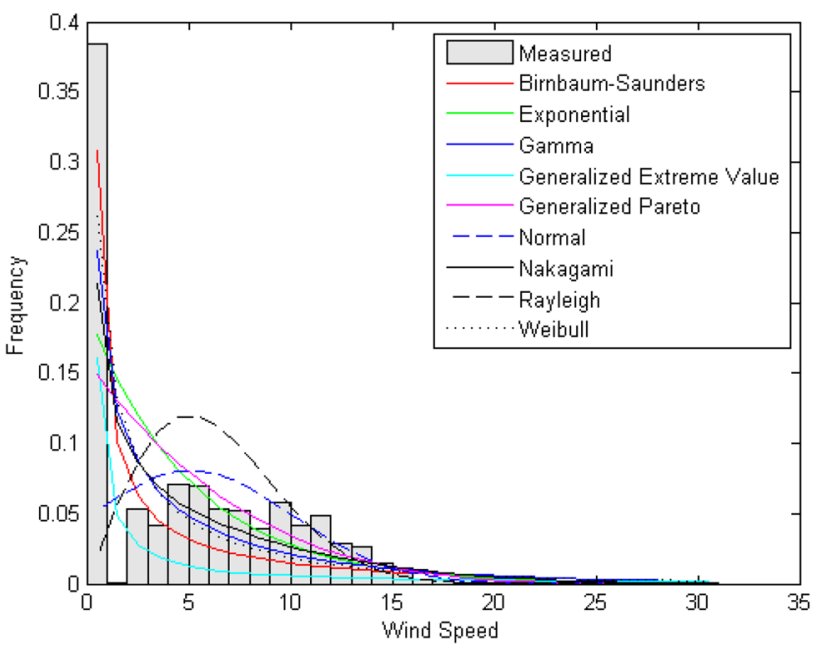

Fig. 5 Wind distribution at Piarco

\section{Goodness of fit}

After plotting the distributions using the estimated parameters, the goodness of fit of the distributions to the data profile were assessed using the following metrics:

- Normalised mean square error (NMSE).

- Chi-squared statistic.

- Two sample.

- Kolmogorov-Smirnov.

- Coefficient of determination $\left(R^{2}\right)$.

- Akaike information criterion (AIC).

- Bayseian information criterion (BIC). 


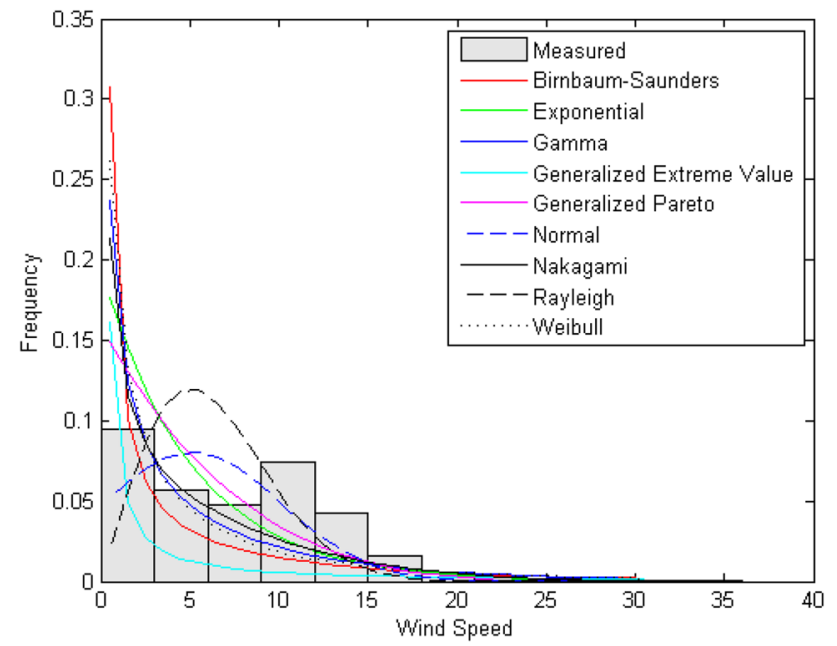

Fig. 6 Wind distribution at Crown Point (Bin Size 3)

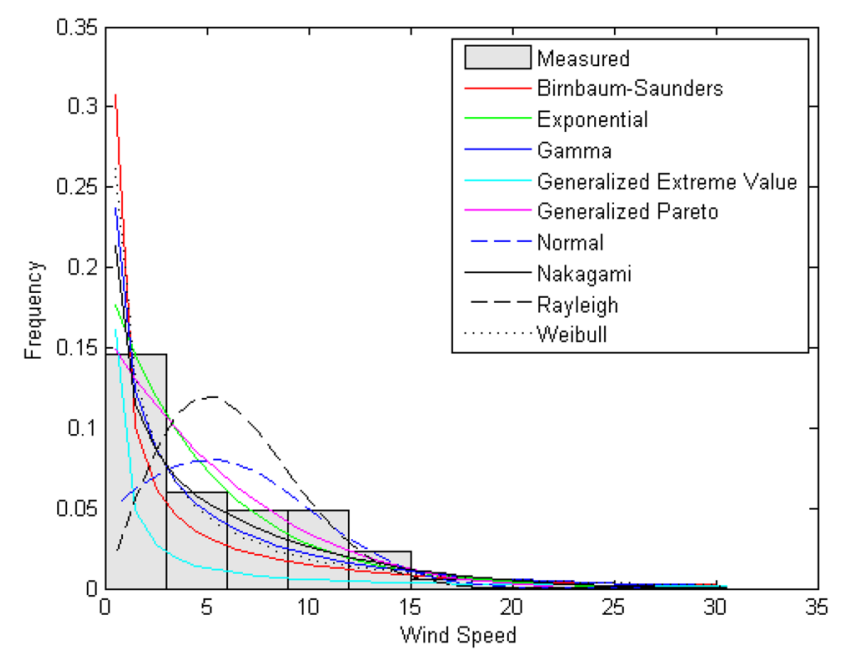

Fig. 7 Wind distribution at Piarco (Bin Size 3)
The normalised mean square error (NMSE)

The NMSE was calculated using the previous method with the following equation:

$\mathrm{NMSE}=1-\sum_{i=1}^{n}\left(\frac{y_{i}-f_{i}}{y_{i}-\hat{f}_{i}}\right)^{2}$

Where $y_{n}$ are the modelled values and $f_{n}$ are the reference data.

The returned value varies between $-\infty$ (bad fit) to 1 (perfect fit) $[50,51]$.

\section{The Chi-squared statistic}

For testing the goodness of fit, the Chi-squared was used. The Chi-square statistic $\left(\chi^{2}\right)$ is calculated as follows:

$\chi^{2}=\sum_{i=1}^{N} \frac{\left(O_{i}-E_{i}\right)^{2}}{E_{i}}$,

where $O_{i}$ are the observed counts and $E_{i}$ are the expected counts [49]. $O_{i}$ was the estimated sample datasets calculated using the estimated pdf of each distribution. $E_{i}$ was derived via the frequency histogram based on the measured data. $N$ was determined by the number of bins used in the frequency histogram. A smaller Chi-squared statistic indicates a better fit.

\section{The two-sample Kolmogorov-Smirnov test}

The two-sample Kolmogorov-Smirnov test statistic was calculated as follows:

$D^{*}=\max _{x}\left(\left|F_{1}(x)-F_{2}(x)\right|\right)$
Table 6 Distribution ranking for Crown Point data (Bin Size 1)

\begin{tabular}{llllll}
\hline Rank & NMSE & X2 & KS & $R^{2}$ and $R^{2}$ Adj & LogL, AIC and BIC \\
\hline 1 & Nakagami & Normal & Normal & Nakagami & Birn-Saun \\
2 & Weibull & Gen. ext val & Gen. ext val & Gamma & Nakagami \\
3 & Gamma & Rayleigh & Rayleigh & Weibull & Gamma \\
4 & Exponential & Gen. Pareto & Gen. Pareto & Gen. Pareto & Weibull \\
5 & Gen. Pareto & Exponential & Exponential & Exponential & Gen. Pareto \\
6 & Rayleigh & Nakagami & Nakagami & Birn-Saun & Exponential \\
7 & Normal & Gamma & Weibull & Gen. ext val & Gen. ext val \\
8 & Gen. ext val & Weibull & Birn-Saun & Normal & Normal \\
9 & Birn-Saun & Birn-Saun & Gamma & Rayleigh & Rayleigh \\
\hline
\end{tabular}


Table 7 Distribution ranking for Piarco data (Bin Size 1)

\begin{tabular}{llllll}
\hline Rank & NMSE & X2 & KS & $R^{2}$ and $R^{2}$ Adj & LogL, AIC and BIC \\
\hline 1 & Birn-Saun & Normal & Normal & Birn-Saun & Gen. ext val \\
2 & Weibull & Gen. Pareto & Gen. Pareto & Weibull & Birn-Saun \\
3 & Gamma & Exponential & Rayleigh & Gamma & Nakagami \\
4 & Nakagami & Nakagami & Exponential & Nakagami & Gamma \\
5 & Exponential & Gamma & Nakagami & Gen. ext val & Weibull \\
6 & Gen. Pareto & Rayleigh & Weibull & Exponential & Exponential \\
7 & Rayleigh & Birn-Saun & Gen. ext val & Gen. Pareto & Gen. Pareto \\
8 & Gen. ext val & Weibull & Birn-Saun & Normal & Normal \\
9 & Normal & Gen. ext val & Gamma & Rayleigh & Rayleigh \\
\hline
\end{tabular}

Table 8 Distribution ranking for Crown Point data (Bin Size 3)

\begin{tabular}{llllll}
\hline Rank & NMSE & X2 & KS & $R^{2}$ and $R^{2} 2$ Adj & LogL, AIC and BIC \\
\hline 1 & Gen. Pareto & Normal & Normal & Gen. Pareto & Birn-Saun \\
2 & Exponential & Gen. ext val & Gen. ext val & Exponential & Nakagami \\
3 & Gen. ext val & Rayleigh & Rayleigh & Gen. ext val & Gamma \\
4 & Normal & Gen. Pareto & Gen. Pareto & Nakagami & Weibull \\
5 & Nakagami & Exponential & Exponential & Normal & Gen. Pareto \\
6 & Rayleigh & Nakagami & Nakagami & Gamma & Exponential \\
7 & Gamma & Gamma & Birn-Saun & Weibull & Gen. ext val \\
8 & Weibull & Weibull & Weibull & Rayleigh & Normal \\
9 & Birn-Saun & Birn-Saun & Gamma & Birn-Saun & Rayleigh \\
\hline
\end{tabular}

Table 9 Distribution ranking for Piarco data (Bin Size 3)

\begin{tabular}{llllll}
\hline Rank & NMSE & X2 & KS & $R^{2}$ and $R^{2}$ Adj & LogL, AIC and BIC \\
\hline 1 & Exponential & Normal & Rayleigh & Exponential & Gen. ext val \\
2 & Gen. Pareto & Gen. Pareto & Normal & Gen. Pareto & Birn-Saun \\
3 & Weibull & Exponential & Gen. Pareto & Nakagami & Nakagami \\
4 & Gamma & Nakagami & Weibull & Gamma & Gamma \\
5 & Nakagami & Gamma & Gen. ext val & Weibull & Weibull \\
6 & Birn-Saun & Rayleigh & Exponential & Birn-Saun & Exponential \\
7 & Rayleigh & Birn-Saun & Nakagami & Normal & Gen. Pareto \\
8 & Normal & Weibull & Birn-Saun & Rayleigh & Normal \\
9 & Gen. ext val & Gen. ext val & Gamma & Gen. ext val & Rayleigh \\
\hline
\end{tabular}

where $F_{1}(x)$ is the proportion of $x 1$ values less than or equal to $x$, and $F_{2}(x)$ is the proportion of $x 2$ values less than or equal to $x$. The smaller the test statistic the better the fit [52].

\section{Co-efficient of determination, $R^{2}$}

The $R^{2}$ statistic was calculated as follows:

$R^{2}=1-\frac{S S_{\text {res }}}{S S_{\text {tot }}}$

where,

$S S_{\text {res }}=\sum_{i}\left(y_{i}-f_{i}\right)^{2}$, and,

$S S_{\mathrm{res}}=\sum_{i}\left(y_{i}-\bar{y}\right)^{2}$,

where $y_{i}$ represents the dataset and $f_{i}$ represents the modelled values. $R^{2}$ varies between - Inf (bad fit) to 1 (perfect fit) [53].

\section{Akaike information criterion}

The AIC statistic was calculated as follows:

aic $=-2 \log L(\theta)+2 k$, 
Fig. 8 Crown Point-NMSE

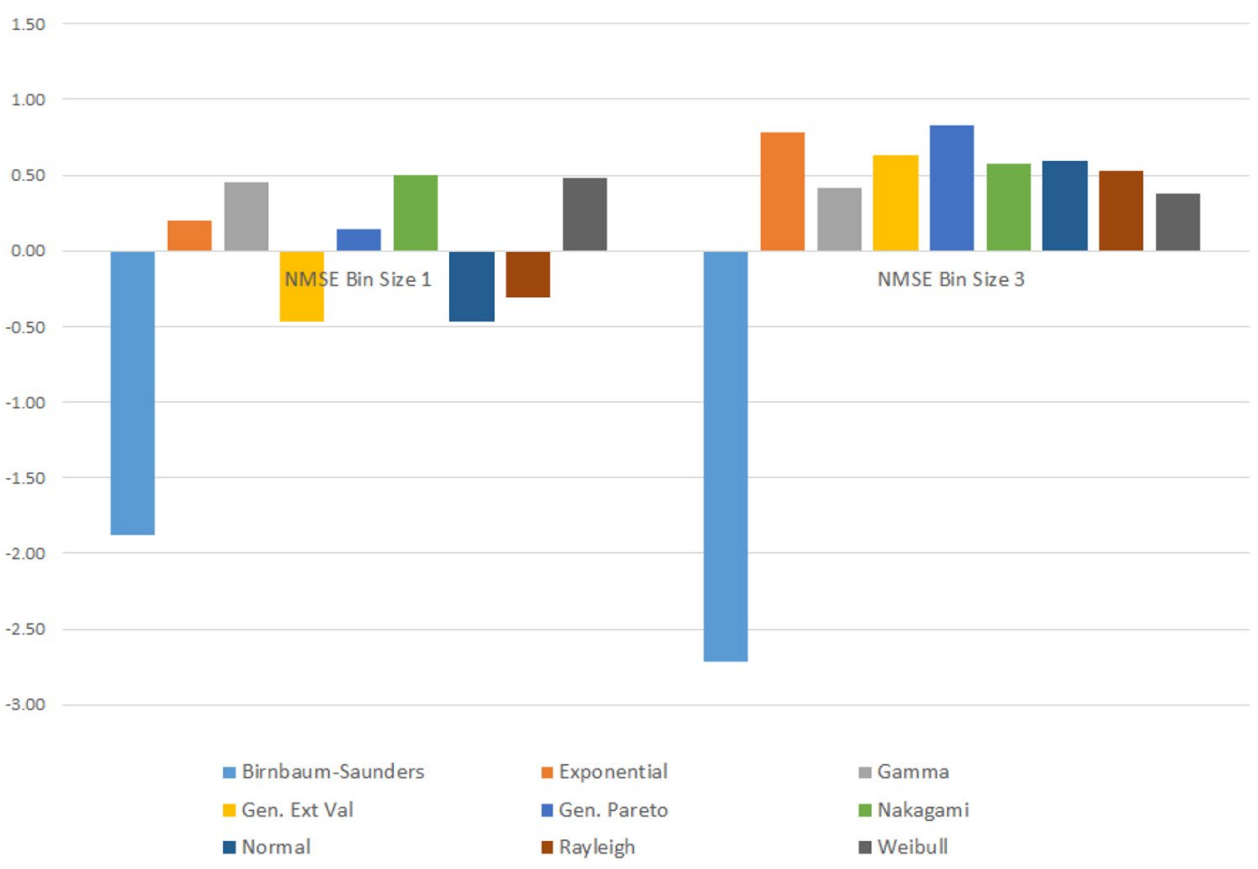

Fig. 9 Crown Point-Chi

300000 Squared

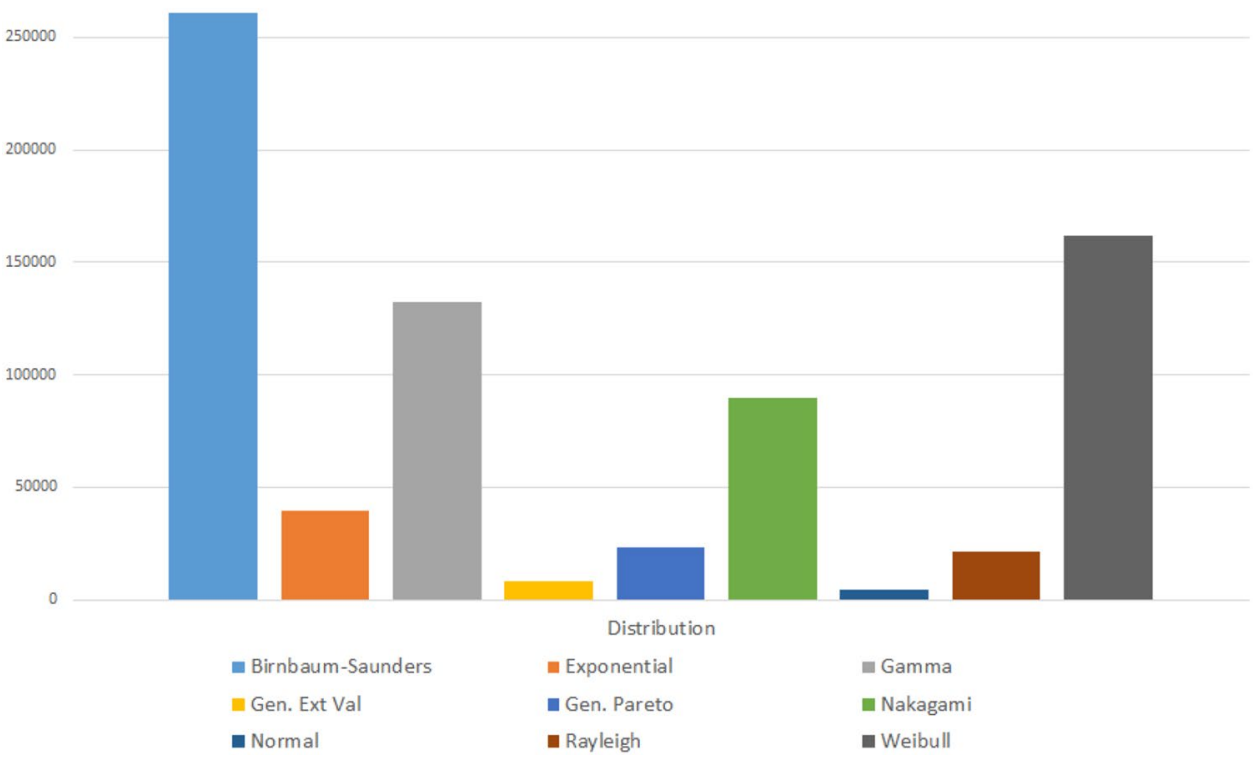

where $\log L(\theta)$ denotes the value of the maximized loglikelihood objective function for a model with $k$ parameters. A smaller AIC statistic value indicates a better fit [54].

\section{Bayesian information criterion}

The BIC statistic was calculated as follows: bic $=-2 \log L(\theta)+k \log (N)$,

where $\log L(\theta)$ denotes the value of the maximized loglikelihood objective function for a model with $k$ parameters fit to $N$ data points. A smaller BIC statistic value indicates a better fit [54] (Figs. 4, 5, 6, 7). 
Fig. 10 Crown Point-KS

0.60

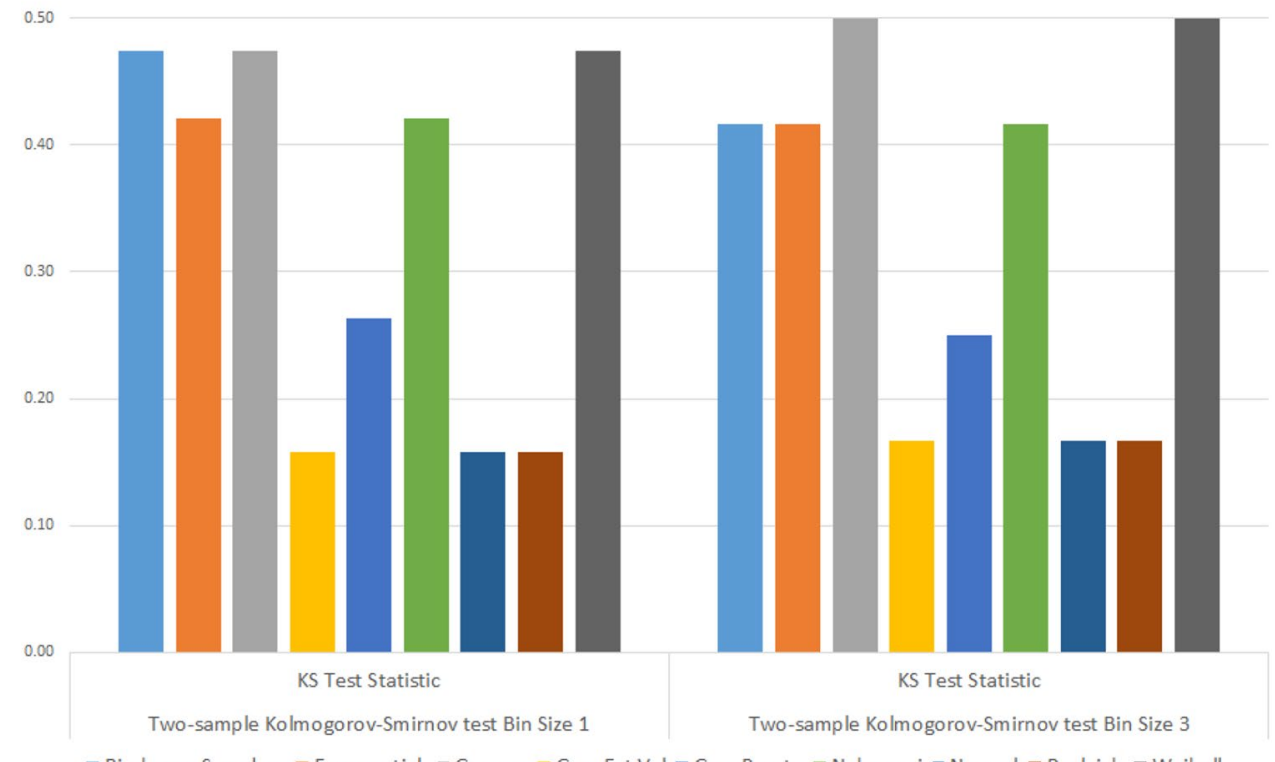

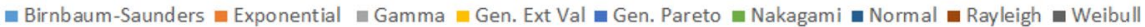

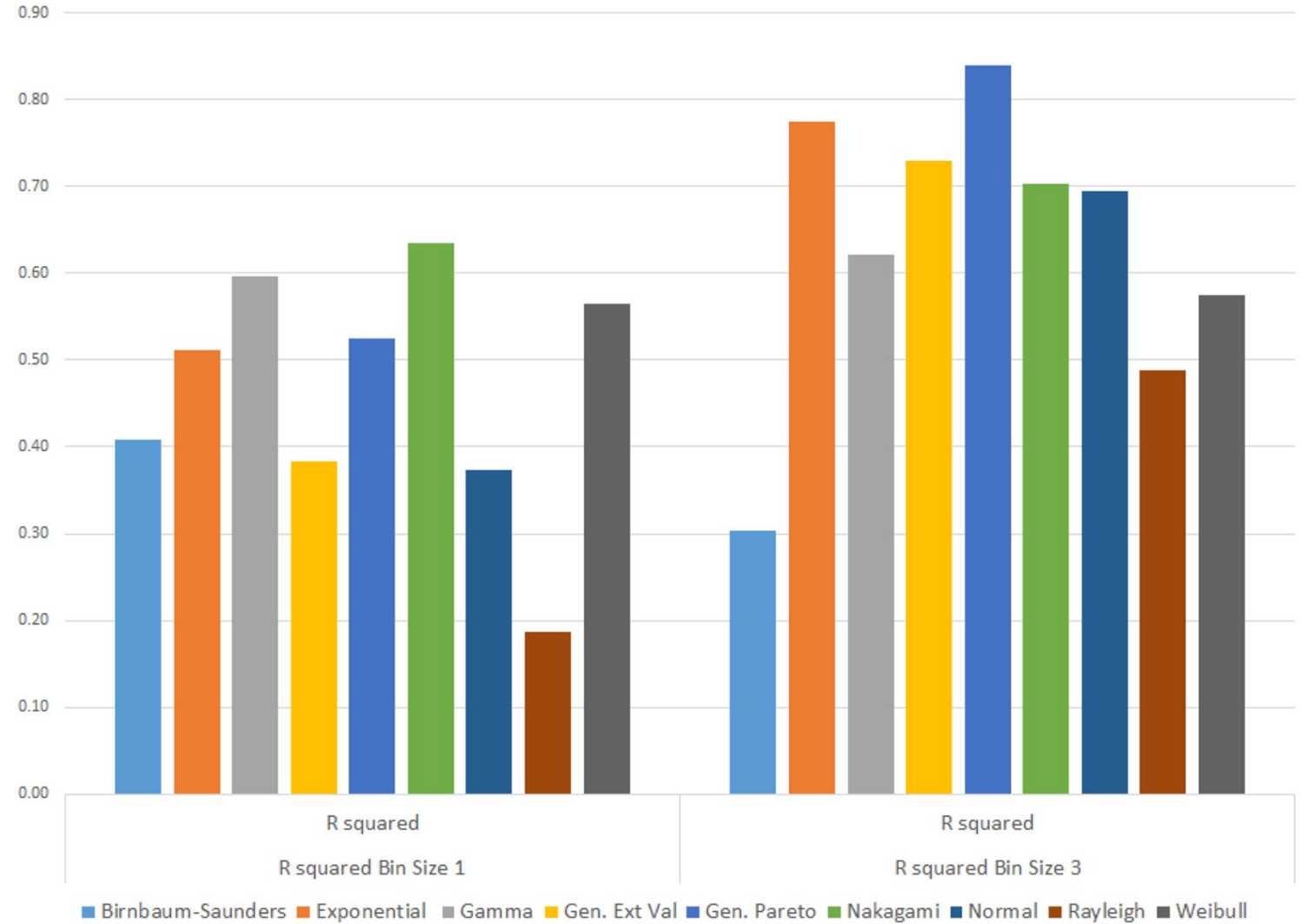

Fig. 11 Crown Point-R Squared 


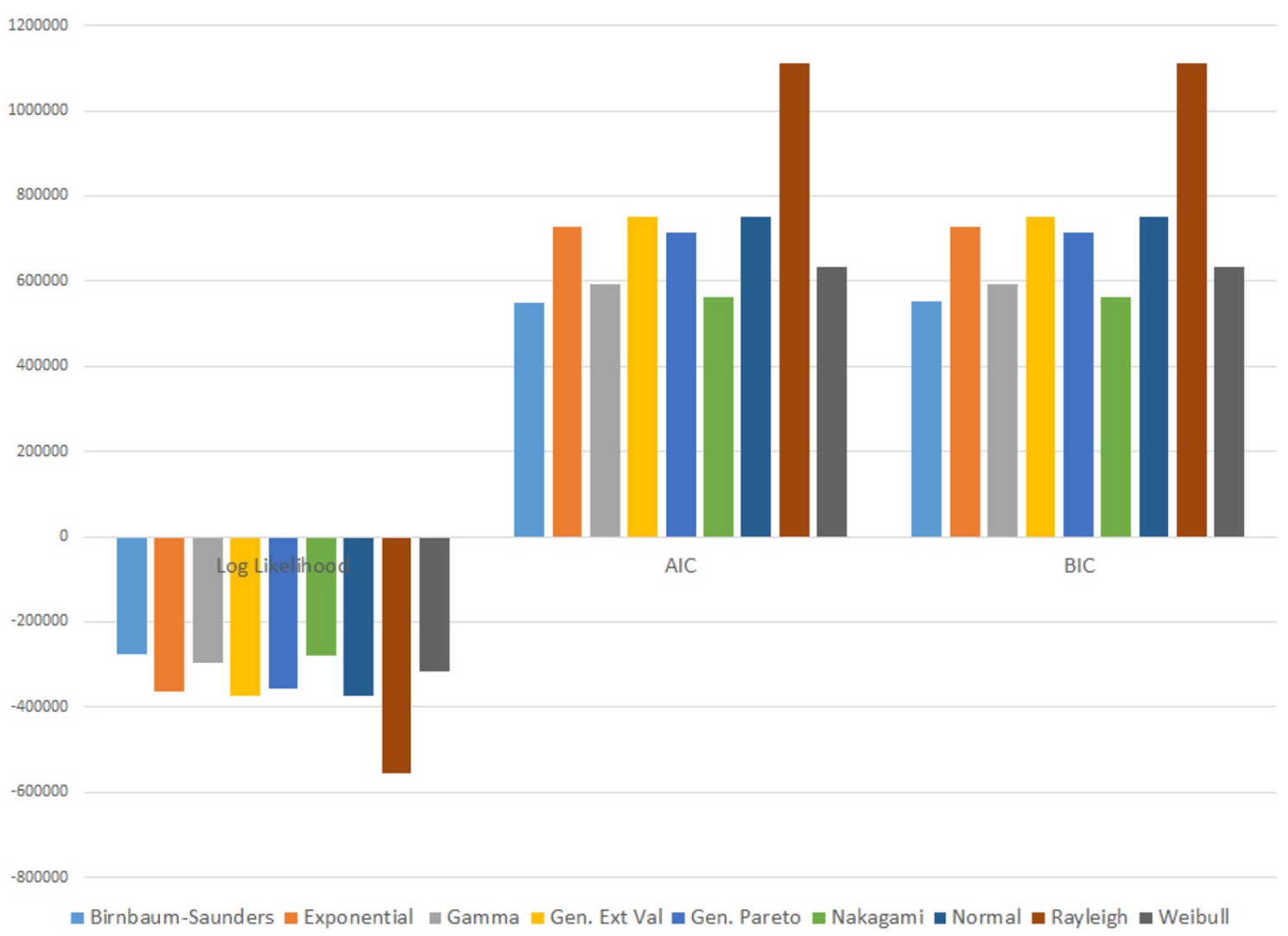

Fig. 12 Crown Point-Log Likelihood, AIC and BIC

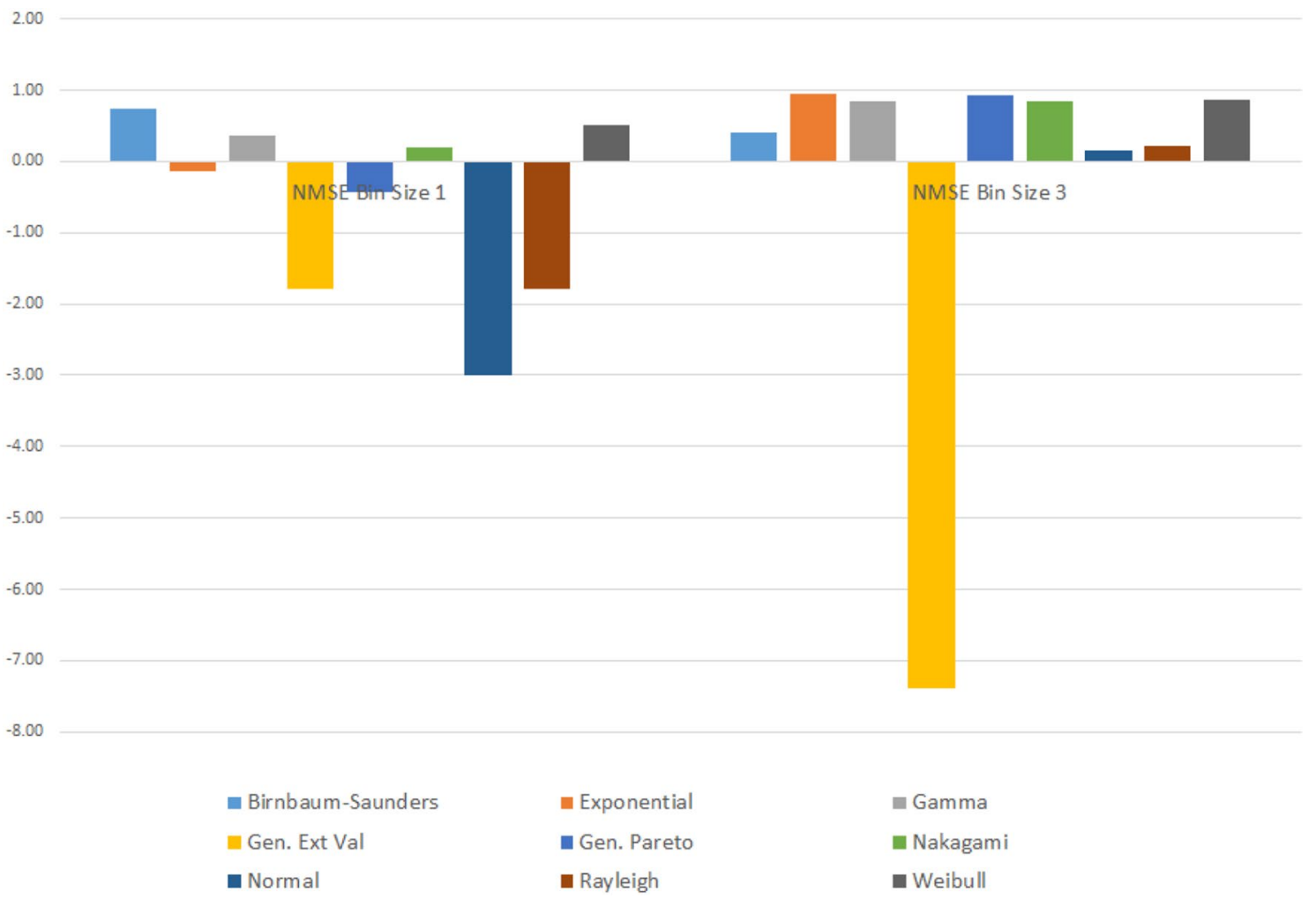

Fig. 13 Piarco-NMSE 


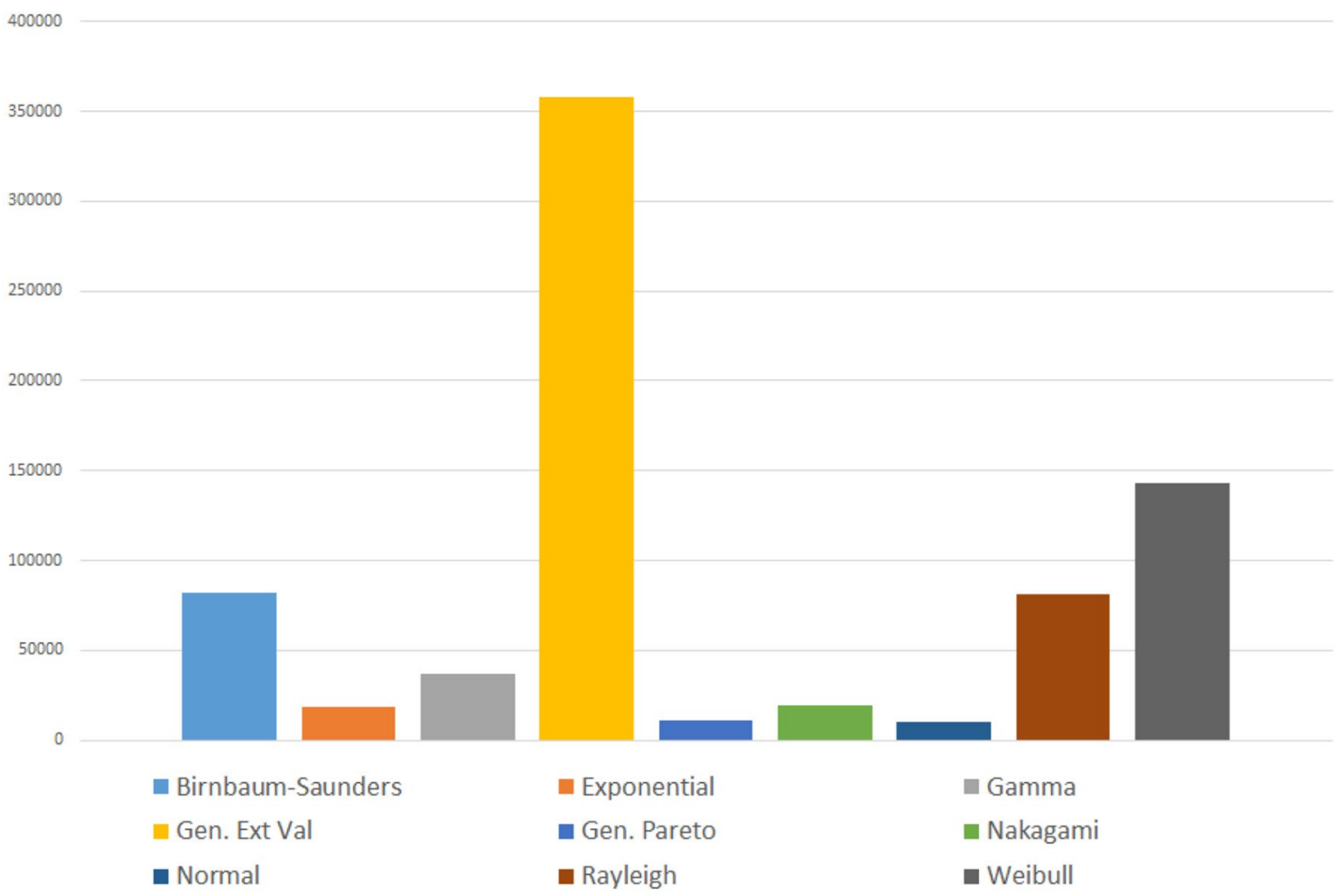

Fig. 14 Piarco-Chi Squared

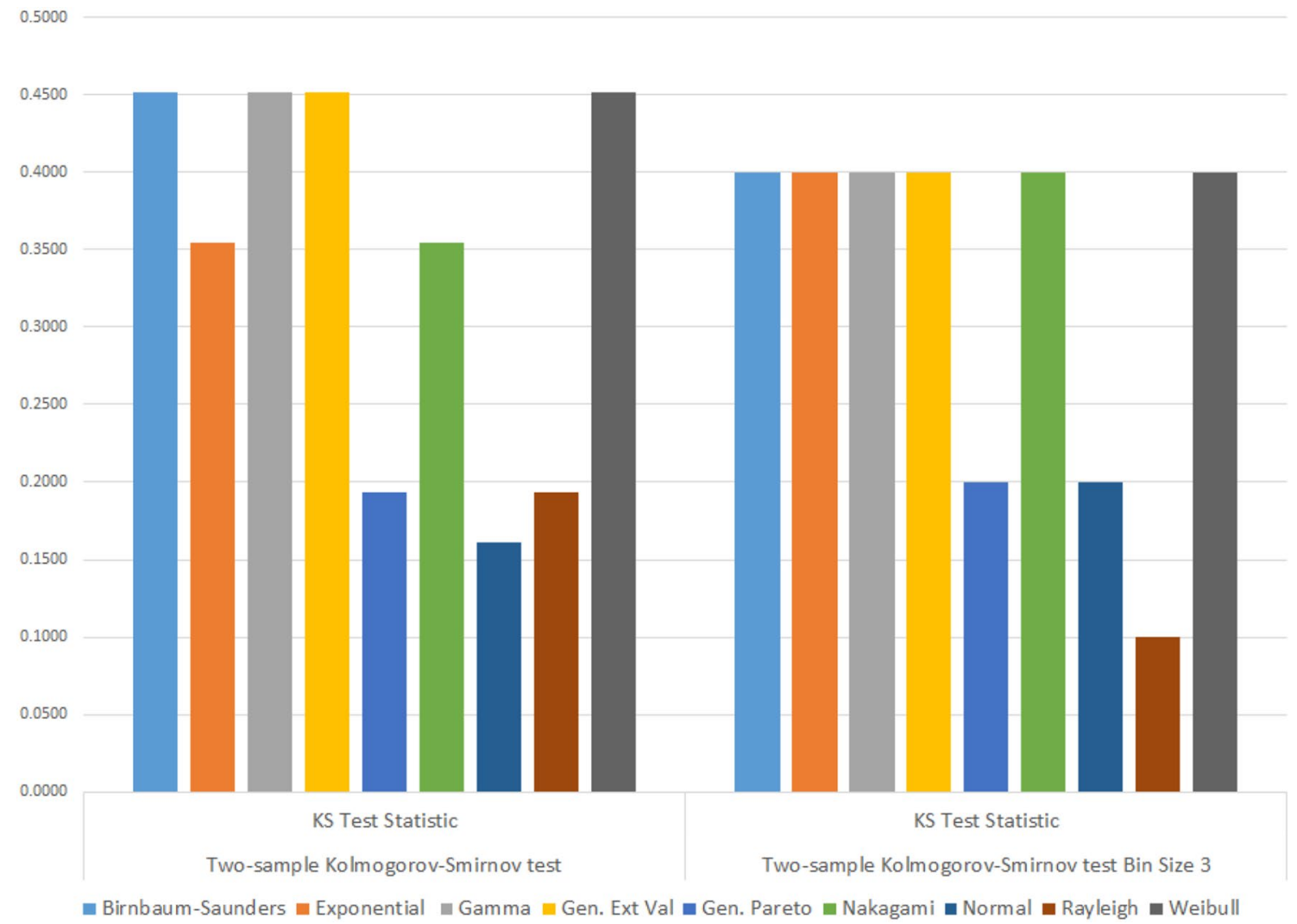

Fig. 15 Piarco—ranked by KS 


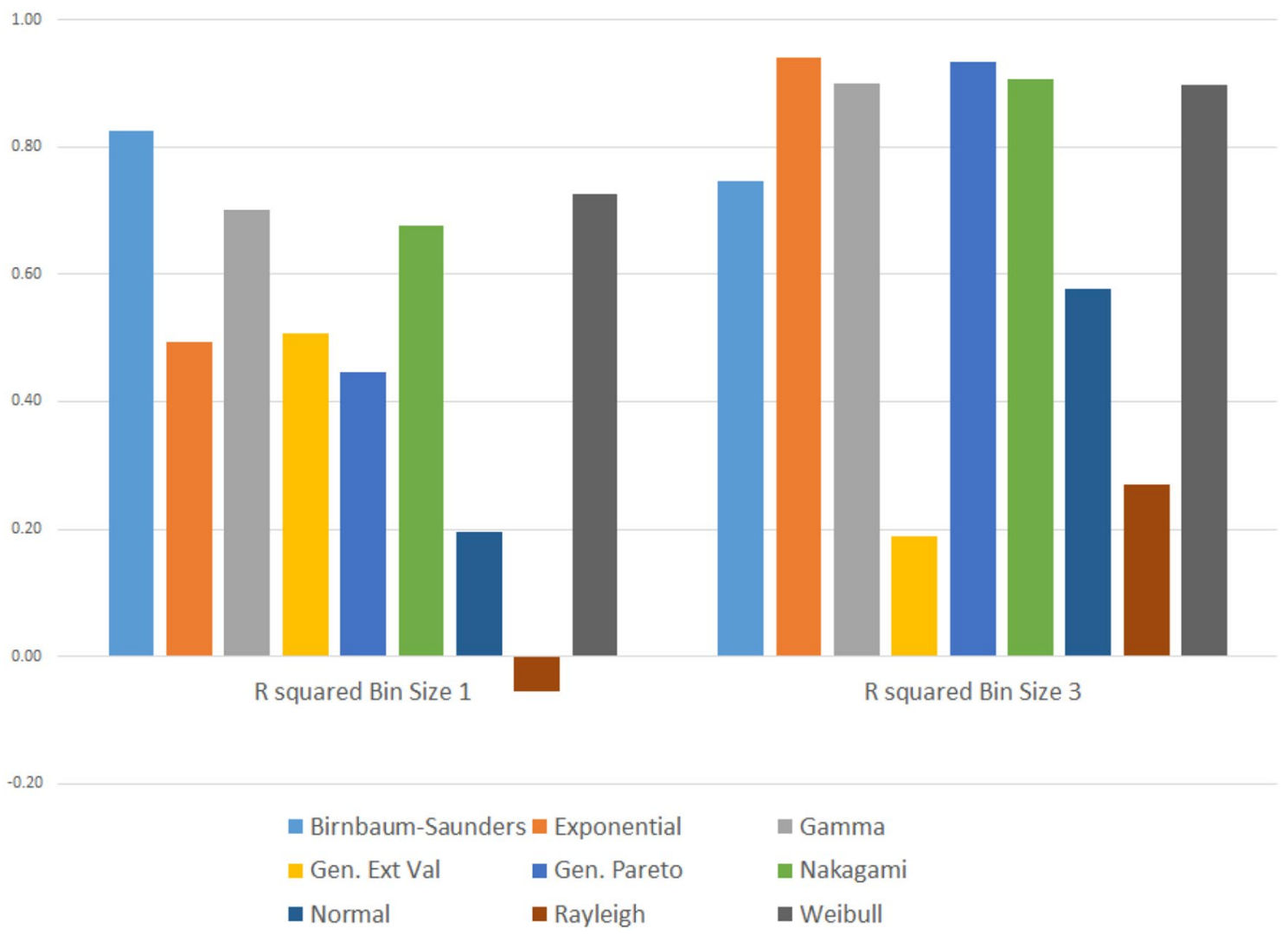

Fig. 16 Piarco-Chi Squared

\section{Results and discussion}

The estimated parameters for each distribution are shown in the Appendix. The performance of these distributions were compared using the goodness of fit metrics described in Sect. 3.4 (Tables 6, 7, 8, 9).

As evident, rankings varied depending on the goodness of fit metric used. Although in some other studies goodness of fit metrics corroborated each other [32, 38, 39], similar variability was observed in [55].

Figures $8,9,10,11,12,13,14,15,16$ and 17 show the details for each goodness of fit metric. This is particularly evident in Figs. 8 and 9 which show rankings by NMSE and Chi-squared metrics, where the Birnbaum-Sanders distribution was particularly ill fitted as compared to Figs. 11 and 12 in which it is comparable when evaluated using the $R^{2}$, and AIC and BIC criteria, respectively.

The variability in rankings raises the question of suitability of any given metric to the application. Consequently, some method of determining which goodness-of-fit criterion is best suited to the application has to be found or a new application-specific information criterion (ASIC) has to be formulated.

\section{Application-specific information criterion}

Wind models are used to calculate the expected energy generated by wind turbines. In this case, expected energy output over a particular time would be an important consideration in design and investment decisions. The ability of the distribution to accurately estimate this value is crucial.

Consider a wind turbine modeled as a 3MW unit using a piecewise linear model with a cut-in speed (cis) of $3.5 \mathrm{~ms}^{-1}$, rated speed $(r s)$ of $14 \mathrm{~ms}^{-1}$ and cut-out speed (cos) of 25 $\mathrm{ms}^{-1}$ as shown in Fig. 18.

The expected energy output of the turbine over a given period of time is calculated according to Eq. 19.

$E=\operatorname{hrs} \times \int_{\text {cis }}^{\cos } P(v) \times f(v) \mathrm{d} v$

where $P(v)$ is the turbine power vs speed characteristic (Fig. 18) and $f(v)$ is the distribution function used to model the data.

For this work, the proposed ASIC is defined as a normalized weighted error function (in this case normalized error in expected energy is used), with the weightings defined by the turbine characteristic. 
1200000

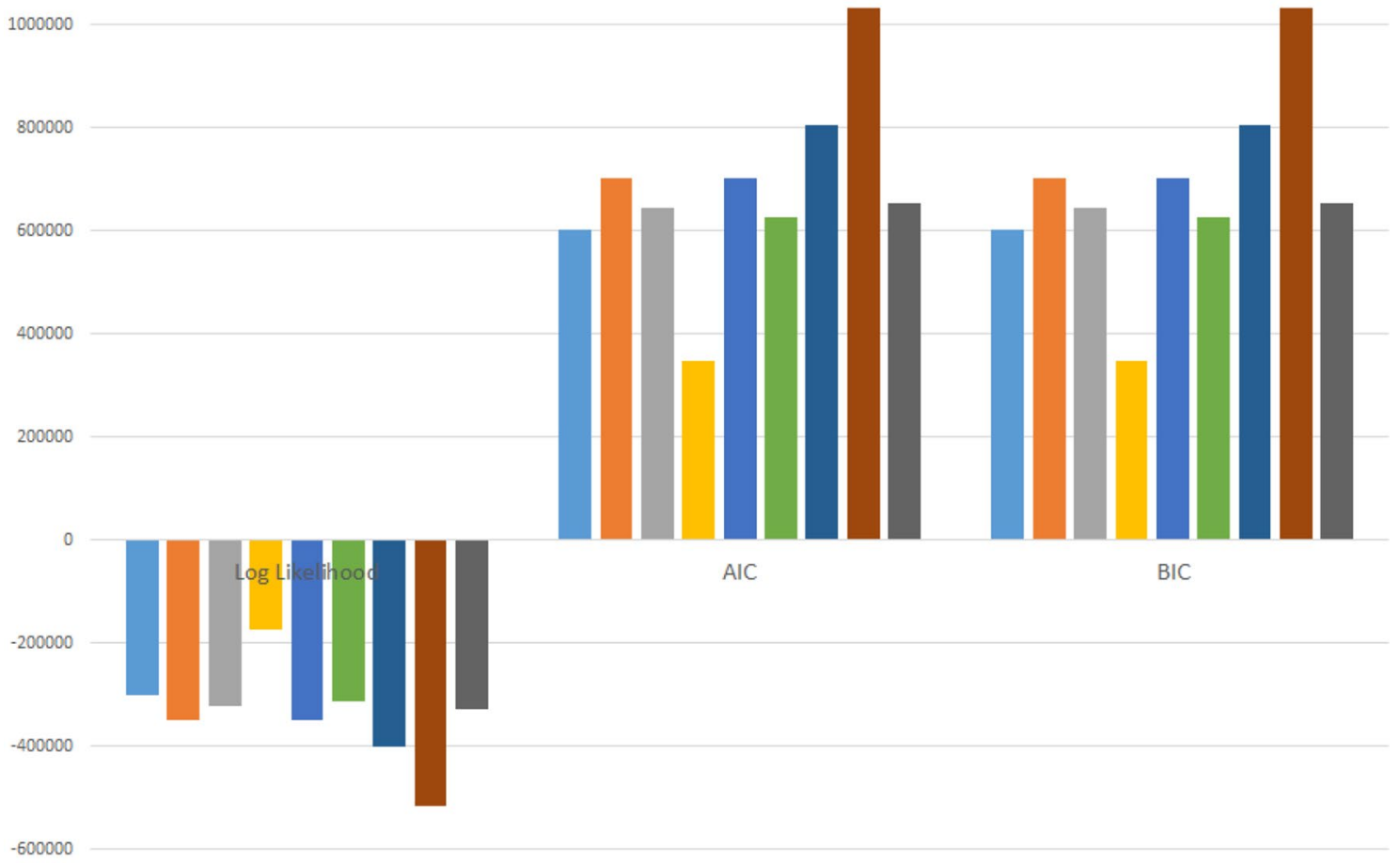

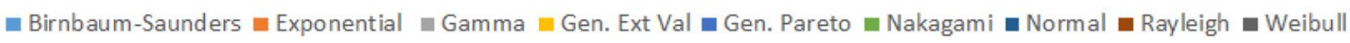

Fig. 17 Piarco-Log-Likelihood, AIC and BIC

Fig. 18 Wind turbine power characteristic

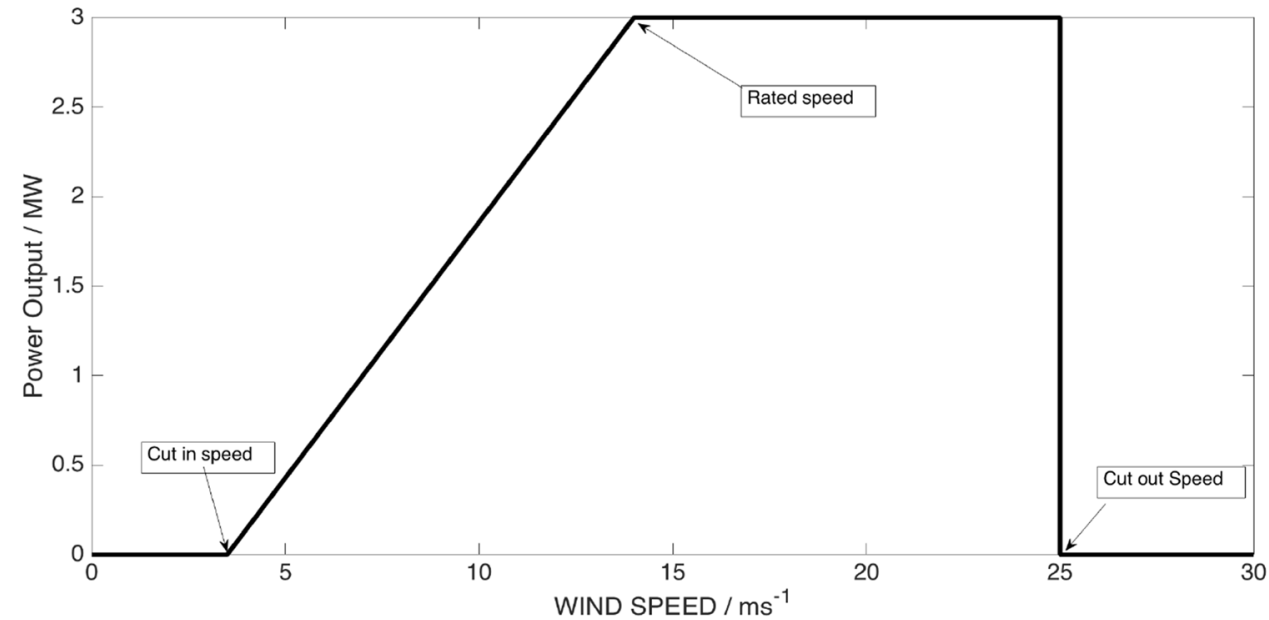

$$
\begin{aligned}
\text { ASIC } & =\frac{\operatorname{hrs} \times\left[\int_{\text {cis }}^{\cos } P(v) \times \hat{f}(v) \mathrm{d} v-\int_{\text {cis }}^{\cos } P(v) \times f(v) \mathrm{d} v\right]}{\operatorname{hrs} \times \int_{\mathrm{cis}}^{\cos } P(v) \times f(v) \mathrm{d} v}, \\
& =\frac{\int_{\operatorname{cis}}^{\cos } P(v) \times(\hat{f}(v)-f(v))}{\int_{\operatorname{cis}}^{\cos } P(v) \times f(v) \mathrm{d} v} \mathrm{~d} v
\end{aligned}
$$

where $\hat{f}(v)$ is the estimated distribution function.

Using this approach, sections of the distribution which contribute more to the application are more heavily weighted than those that do not. In this case, the fit of the distributions below wind speeds of $3.5 \mathrm{~ms}^{-1}$ or above $25 \mathrm{~ms}^{-1}$ are not as important since the wind turbine does not output any power for those conditions. Using the chosen ASIC, the fit of the 
Table 10 Expected energy at Crown Point by distribution

\begin{tabular}{lll}
\hline Distribution & Expected energy/MWh & $\begin{array}{l}\text { \%Difference } \\
\text { from actual }\end{array}$ \\
\hline Actual & 155,270 & 0 \\
Generalized extreme value & 163,810 & 5.50 \\
Generalized Pareto & 142,140 & -8.46 \\
Normal & 139,560 & -10.12 \\
Nakagami & 139,560 & -14.59 \\
Rayleigh & 179,520 & 15.62 \\
Gamma & 81,110 & -47.76 \\
Weibull & 72,843 & -53.09 \\
Birnbaum-Saunders & 295,810 & 90.51 \\
Exponential & $4.0429 \mathrm{E}-08$ & -100 \\
\hline
\end{tabular}

Table 11 Expected energy predicted at Piarco by distribution

\begin{tabular}{lll}
\hline Distribution & Expected energy/MWh & $\begin{array}{l}\text { \%Difference } \\
\text { from actual }\end{array}$ \\
\hline Actual & 111,560 & 0 \\
Normal & 113,930 & 2.12 \\
Nakagami & 121,920 & 9.28 \\
Rayleigh & 123,060 & 10.30 \\
Generalized Pareto & 97,240 & -12.84 \\
Gamma & 77,874 & -30.20 \\
Generalized extreme Value & 71,804 & -35.64 \\
Weibull & 71,187 & -36.19 \\
Exponential & 0.00012435 & -100.00 \\
Birnbaum-Saunders & 403,780 & 261.94 \\
\hline
\end{tabular}

data over the range of power producing speeds of the turbine is assessed. This marks a departure from the philosophy behind other goodness-of-fit tests which equally weight all sections of a distribution or weight them based on probability and do not consider any external information in the determination of goodness of fit.

The actual energy output for Piarco was calculated as approximately $112 \mathrm{GWh}$, while the value for Crown Point was $155 \mathrm{GWh}$. Tables 10 and 11 show the percentage difference in energy predicted by the models as compared to the energy derived directly from the wind data. As evident, the results did not match any ranking derived from the conventional goodness-of-fit metrics.

Among the traditional goodness-of-fit tests, the Chisquared and Kolmogorov-Smirnov tests produced similar results to the ASIC in that they placed similar candidate distributions within the top four ranked distributions, albeit with a different order. This indicates that they may be better suited as goodness-of-fit tests for the purpose of wind energy studies than the other traditional goodness of fit metrics
Table 12 Parameter Estimates for distributions

\begin{tabular}{llll}
\hline \multirow{2}{*}{ Distribution } & & Location \\
\cline { 3 - 4 } Birnbaum-Saunders & Parameter & Crown Point & Piarco \\
\hline \multirow{2}{*}{ Exponential } & gamma & 0.1009 & 1.0274 \\
Gamma & lambda & 7.3244 & 2.6596 \\
& $k$ & 0.3606 & 0.1314 \\
Generalized extreme value & theta & 20.314 & 10.4568 \\
& xi & -0.15 & 4.2971 \\
Generalized Pareto & sigma & 4.9517 & 0.437 \\
& mu & 5.0824 & 0.1016 \\
Nakagami & xi & -0.2299 & -0.2013 \\
Normal & Sigma & 8.7412 & 6.2781 \\
& Theta & 0.0001 & 0.0001 \\
Rayleigh & Mu & 0.1807 & 0.2244 \\
Weibull & omega & 82.1115 & 51.0448 \\
& sigma & 7.3244 & 4.971 \\
& mu & 5.3352 & 5.1314 \\
& sigma & 6.4075 & 5.052 \\
& lamda & 5.3442 & 3.9135 \\
& $k$ & 0.4825 & 0.6195 \\
\hline
\end{tabular}

utilised in this paper. Given that the application space is known, however, using an ASIC would still be preferrable since rankings are made according to a parameter (energy in this case) which is meaningful to users of the data.

Finally, it is also noteworthy that the Weibull distribution, which is traditionally used in wind modelling in the Caribbean, performed poorly for both datasets using all the metrics investigated. This is likely due to the large amount of low to zero wind speed measurements. Castellanos [37] has also noted that the Weibull distribution performs poorly when the data contains a large proportion of low wind speeds (Figs. 19, 20; Table 12).

\section{Conclusions}

The Weibull distribution was found to perform relatively poorly as a wind probability model for both sites. The Rayleigh distribution performed consistently better than the Weibull but was still ill suited as a model for the data.

The inconsistency in results for the goodness of fit led to the conceptualization of application-specific information criteria (ASIC) as a more meaningful approach for assessment of goodness of fit in cases where the secondary, applicationspecific features must be calculated from the primary data.

For the application in question, the normalized error in expected energy is used as a goodness-of-fit metric to rank candidate distributions. The advantage of this technique 
Fig. 19 Crown Point ranked by expected energy
150.0

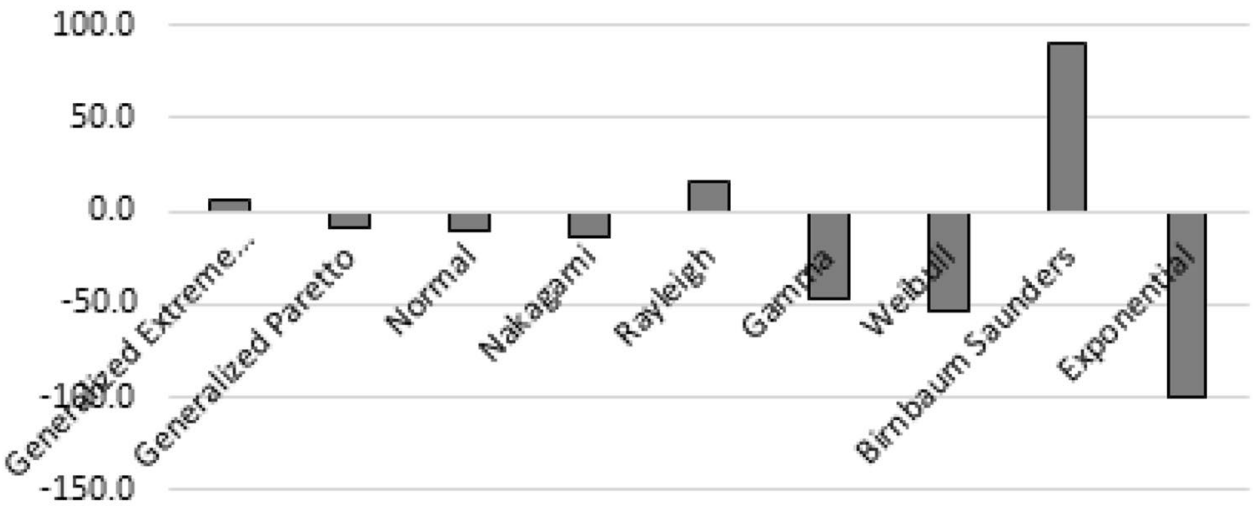

300.0

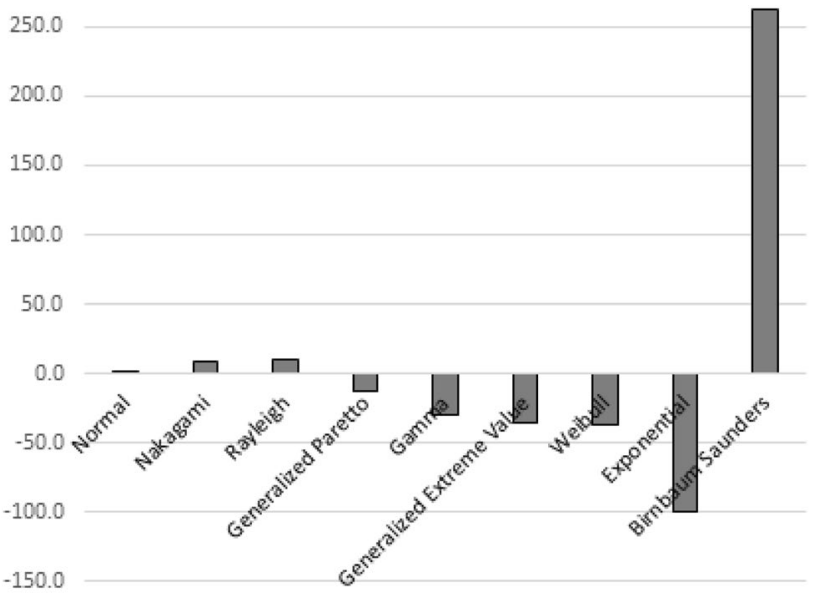

$\square \%$ Differencefrom actual

Fig. 20 Piarco ranked by expected energy

is that the distributions can be examined in terms of overestimation or under-estimation of expected energy as well as the magnitude of deviation while using a metric that is meaningful in the context of the intended application space.

Open Access This article is distributed under the terms of the Creative Commons Attribution 4.0 International License (http://creativecommons.org/licenses/by/4.0/), which permits unrestricted use, distribution, and reproduction in any medium, provided you give appropriate credit to the original author(s) and the source, provide a link to the Creative Commons license, and indicate if changes were made.

\section{References}

1. Bailey, J., Janson, N.: Pre-Feasibility Study of the Potential Market for Natural Gas as a Fuel for Power Generation in the Caribbean. Report, Inter-American Development Bank (2013)

2. Yepez-García, R., Johnson, T. M., Andrés, L.A.: Meeting the electricity supply/demand balance in Latin America \& the Caribbean. The World Bank, Washington, DC

3. Sharma, C., Bahadoorsingh, S., Aiyejina, A.: Integrating applicable sources of renewable energy in the Caribbean. In: Power and Energy Society General Meeting. IEEE, pp. 1-6 (2011)

4. Bahadoorsingh, S., Ramdathsingh, R., Sharma, C.: Integrating wind energy in a Caribbean island: A case study of Anguilla. In: Transmission and Distribution Conference and Exposition). IEEE PES, pp. 1-8 (2012)

5. Weisser, D.: A wind energy analysis of Grenada: an estimation using the 'Weibull' density function. Renew. Energy 28(11), 1803-1812 (2003)

6. Sharma, C., Chadee, J.: A wind energy conversion system (WECS) for the Island Of Tobago-a case study. Energy Eng. 96(3)

7. Persaud, S., Flynn, D., Fox, B.: Potential for wind generation on the Guyana coastlands. Renew. Energy 18(2), 175-189 (1999)

8. http://www.emdaews.net/2013/08/caribbean-economies-batteredby-storms/. Accessed 13 Mar 2018

9. http://www.emdat.be. Accessed 13 Mar 2018

10. Acevedo, T.-J.: Cebotari, IMF-Caribbean Small States: Challenges of High Debt and Low Growth. Report, International Monetary Fund (2013)

11. Ouattara, B., Strobl, E.: The fiscal implications of hurricane strikes in the Caribbean. Ecol. Econ. 85, 105-115 (2013)

12. Nyberg, J.: Luminescence intensity in coral skeletons from Mona Island in the Caribbean Sea and its link to precipitation and wind speed. Philos. Trans. R. Soc. Lond. Ser. A Math. Phys. Eng. Sci. 360(1793), 749-766 (2002)

13. Oliveira, A.P., Bornstein, R.D., Soares, J.: Annual and diurnal wind patterns in the city of São Paulo. Water Air Soil Pollut. Focus 3(5-6), 3-15 (2003)

14. http://www.wunderground.com/history/airport/ TTPP/2009/7/12/DailyHistory.html. Accessed 13 Mar 2018

15. Ettoumi, F.Y., Sauvageot, H., Adane, A.-E.-H.: Statistical bivariate modelling of wind using first-order markov chain and weibull distribution. Renew. Energy 28(11), 1787-1802 (2003) 
16. Hennessey Jr., J.P.: A comparison of the weibull and Rayleigh distributions for estimating wind power potential. Wind Eng. 2, 156-164 (1978)

17. Rajabi, M., Modarres, R.: Extreme value frequency analysis of wind data from Isfahan, Iran. J. Wind Eng. Ind. Aerodyn. 96(1), 78-82 (2008)

18. Celik, A.N.: A statistical analysis of wind power density based on the Weibull and Rayleigh models at the southern region of Turkey. Renew. Energy 29(4), 593-604 (2004)

19. Holmes, J.D., Moriarty, W.W.: Application of the generalized pareto distribution to extreme value analysis in wind engineering. J. Wind Eng. Ind. Aerodyn. 83(1-3), 1-10 (1999)

20. Agustin, E.-S.C.: Estimation of extreme wind speeds by using mixed distributions. Ingeniería Investigación y Tecnología 14(2), 153-162 (2013)

21. Akpinar, E.K., Akpinar, S.: Determination of the wind energy potential for Maden-Elazig,Turkey. Energy Convers. Manag. 45(18-19), 2901-2914 (2004)

22. Carta, J.A., Ramirez, P., Velazquez, S.: A review of wind speed probability distributions used in wind energy analysis: Case studies in the Canary Islands. Renew. Sustain. Energy Rev. 13(5), 933-955 (2009)

23. Admiralty, South American, Pilot: second. Admiralty Sailing Directions, vol. IV. United Kingdom Hydrographic Office, Somerset (1983)

24. https://www.google.tt/maps/@ 10.6902115,-61.1242987,19867 $0 \mathrm{~m} / \mathrm{data}=! 3 \mathrm{~m} 1 ! 1 \mathrm{e} 3 ? \mathrm{hl}=\mathrm{en}$. Accessed $13 \mathrm{Mar} 2018$

25. Schott, T., Landsea, C., Hafele, G., Lorens, J., Taylor, A., Thurm, H., Ward, B., Willis, M., Zaleski, W.: The saffir-simpson hurricane wind scale, National Weather Services, National Hurricane Centre, National Oceanic and Atmospheric Administration (NOAA) factsheet. http://www.nhc.noaa.gov/pdf/sshws.pdf

26. Kimberlain, T., Blake, E., Cangialosi, J.: Hurricane patricia (ep202015), National Hurricane Center tropical cyclone report

27. http://www.wunderground.com/history/airport/TTPP/2014/7/3/ DailyHistory.html?req_city $=$ Piarco+International\&req_state $=\&$ req_statename $=$ Trinidad + And + Tobago\&reqdb.zip $=00000$ \&reqdb.magic $=3 \&$ reqdb.wmo=78970. Accessed 13 Mar 2018

28. http://www.guardian.co.tt/archives/searchcontent?title=\&field _date_value[value][date]=2009-07-13\&field_authors_ tid=All\&field_topic_tid=All. Accessed 13 Mar 2018

29. Karatepe, S., Corscadden, K.W.: Wind speed estimation: Incorporating seasonal data using markov chain models. ISRN Renew. Energy, 1-9 (2013)

30. Corotis, R.B., Sigl, A.B., Klein, J.: Probability models of wind velocity magnitude and persistence. Sol. Energy 20(6), 483-493 (1978)

31. Kaminsky, F.: Four probability densities/log-normal, gamma, weibull, and rayleigh/and their application to modelling average hourly wind speed. In: International Solar Energy Society, Annual Meeting, vol. 1, pp. 19-6 (1977)

32. Akpinar, E.K.: A statistical investigation of wind energy potential. Energy Sources Part A Recover. Util. Environ. Eff. 28(9), 807-820 (2006)

33. Chadee, J., Sharma, C.: Wind speed distributions: a new catalogue of defined models. Wind Eng. 25(6), 319-337 (2001)

34. Simiu, E., Heckert, N.: Extreme wind distribution tails: a "peaks over threshold" approach. J. Struct. Eng. 122(5), 539-547 (1996)

35. Sarkar, A., Singh, S., Mitra, D.: Wind climate modeling using Weibull and extreme value distribution. Int. J. Eng. Sci. Technol. 3(5)
36. Akpinar, E.K., Akpinar, S.: An assessment on seasonal analysis of wind energy characteristics and wind turbine characteristics. Energy Convers. Manage. 46(11-12), 1848-1867 (2005)

37. Castellanos, F., Ramesar, V.I.: Characterization and estimation of wind energy resources using autoregressive modelling and probability density functions. Wind Eng. 30(1), 1-14 (2006)

38. Shamilov, A., Kantar, Y.M., Usta, I.: Use of minmaxent distributions defined on basis of maxent method in wind power study. Energy Convers. Manage. 49(4), 660-677 (2008)

39. Alavi, O., Mohammadi, K., Mostafaeipour, A.: Evaluating the suitability of wind speed probability distribution models: A case of study of east and southeast parts of Iran. Energy Convers. Manage. 119, 101-108 (2016)

40. Leiva, V.: The Birnbaum-Saunders Distribution. Academic Press, Cambridge (2016) (book section Genesis of the Birnbaum-Saunders Distribution, pp. 1-15)

41. Balakrishnan, K.: Exponential distribution: theory, methods and applications. CRC press, Boca Raton (1996)

42. Olver, F.W.: NIST Handbook of Mathematical Functions Hardback and CD-ROM. Cambridge University Press, Cambridge (2010)

43. Hogg, R.V., McKean, J.W., Craig, A.T.: Introduction to mathematical statistics. Pearson Education, Prentice Hall (2005)

44. Coles, S., Bawa, J., Trenner, L., Dorazio, P.: An introduction to statistical modeling of extreme values, vol. 208. Springer, New York (2001)

45. Johnson, N.L., Kotz, S., Balakrishnan, N.: Continuous multivariate distributions, vol. 1, models and applications, vol. 59. Wiley, New York (2002)

46. Nakagami, M.: The m-distribution-a general formula of intensity distribution of rapid fading. Statistical Method of Radio Propagation

47. Weisstein, E.W.: CRC concise encyclopedia of mathematics. CRC Press, Boca Raton (2002)

48. Johnson, N.L., Kotz, S., Balakrishnan, N.: Continuous univariate distributions, vol. 1. Wiley, New York, p. 163 (1994)

49. Leon-Garcia, A.: Probability, statistics and random processes for electrical engineering. Pearson (2008)

50. McCuen, R.H., Knight, Z., Cutter, A.G.: Evaluation of the nashsutcliffe efficiency index. J. Hydrol. Eng. 11(6), 597-602 (2006)

51. Gupta, H.V., Kling, H.: On typical range, sensitivity, and normalization of mean squared error and nash-sutcliffe efficiency type metrics. Water Resour. Res. 47(10)

52. Massey Jr., F.J.: The kolmogorov-smirnov test for goodness of fit. J. Am. Stat. Assoc. 46(253), 68-78 (1951)

53. Neter, J., Kutner, M.H., Nachtsheim, C.J., Wasserman, W.: Applied linear statistical models, vol. 4. Irwin, Chicago (1996)

54. Box, G.E., Jenkins, G.M., Reinsel, G.C., Ljung, G.M.: Time series analysis: forecasting and control. Wiley, New York (2015)

55. Shamilov, A., Usta, I., Kantar, Y.M.: The distribution of minimizing maximum entropy: alternative to weibull distribution for wind speed. WSEAS Trans. Math. 5(6), 695 (2006)

Publisher's Note Springer Nature remains neutral with regard to jurisdictional claims in published maps and institutional affiliations. 